\title{
Acute compartment syndrome
}

\author{
Alessio Giai Via ${ }^{1}$ \\ Francesco Oliva ${ }^{1}$ \\ Marco Spoliti ${ }^{2}$ \\ Nicola Maffulli ${ }^{3}$
}

1 Department of Orthopaedic and Traumatology, University of Rome "Tor Vergata", School of Medicine, Rome, Italy

2 Department of Orthopaedics and Traumatology, San Camillo-Forlanini Hospital, Rome, Italy

3 Department of Musculoskeletal Disorders, School of Medicine and Surgery, University of Salerno, Italy; Queen Mary University of London, Barts and the London School of Medicine and Dentistry, Centre for Sports and Exercise Medicine, London, England

Corresponding author:

Alessio Giai Via

Department of Orthopaedic and Traumatology, University of Rome "Tor Vergata", School of Medicine

Viale Oxford 81

00133 Rome, Italy

E-mail: alessiogiaivia@hotmail.it

\section{Summary}

Background: acute compartment syndrome (ACS) is one of the few true emergencies in orthopedics and traumatology. It is a painful condition caused by the increase interstitial pressure (intracompartmental pressure - ICP) within a closed osteofascial compartment which impair local circulation. It occurs most often in the legs, but it can affects also the arms, hands, feet, and buttocks. It usually develops after a severe injury such as fractures or crush injury, but it can also occurs after a relatively minor injury and it may be iatrogenic. Uncommon causes of ACS have been also described, that suggest surgeons to pay great attention to this serious complication. Diagnosing ACS is difficult in clinical practice, even among expert surgeons. Currently, the diagnosis is made on the basis of physical examination and repeated ICP measures. ICP higher than $30 \mathrm{mmHg}$ of diastolic blood pressure is significant of compartment syndrome.

Once diagnosis is made, fasciotomy to release the affected compartment should be performed as early as possible because delayed decompres- sion would lead to irreversible ischemic damage to muscles and peripheral nerves.

Conclusion: acute compartment syndrome is a surgical emergency. There is still little consensus among authors about diagnosis and treatment of these serious condition, in particular about the ICP at which fasciotomy is absolutely indicated and the timing of wound closure. New investigations are needed in order to improve diagnosis and treatment of ACS.

KEY WORDS: acute compartment syndrome, fasciotomy, intracompartmental pressure, complications, myofascial compartment, fracture.

\section{Introduction}

Compartment syndrome is a painful condition caused by the increased intracompartmental pressure (ICP) within a closed osteofascial compartment. It is both acute and chronic. Acute compartment syndrome (ACS) is a surgical emergency, and unless the pressure is relieved quickly, necrosis of the soft tissues and permanent disability may occur. Schwartz et al. ${ }^{1}$ reported a mortality rate of $47 \%$ after ACS of the thigh. It usually develops after severe injuries such as fractures or crush injury, but it can occurs after a relatively minor injury, or it may be iatrogenic ${ }^{2}$. Usually the leg and forearm are the most frequently affected, but it can also involves the harm, hand, foot, and buttock (Tab. 1).

The average annual incidence of ACS have been estimated form 1 to 7.3 per $100,000^{3}$. It occurs more frequently in male than female. Men were 10 times more likely to suffer ACS than women. The mean age is also different, about 30 years for men and 44 years for women. So the typical patient at risk for ACS is a man younger than 35 years of age, involved in a high energy trauma resulting in a tibial shaft fracture ${ }^{4}$.

\section{The aetiology and pathophysiology of ACS}

Several studies showed that fractures are the most common cause of ACS, accounting for about $69-75 \%$ of cases 5,6 . Lower-leg acute compartment syndrome has been reported in 2 to $9 \%$ of tibial fractures ${ }^{6}$.

It is important to remind that, contrary to the common belief, there is no difference between the ACS of open and closed fractures ${ }^{7}$. Many surgeons think that open fractures naturally decompress the compart- 
Table 1. Anatomical compartments and surgical approaches.

\begin{tabular}{lll}
\hline Anatomical region & Compartments & Surgical approach \\
\hline Forearm & Three: volar, dorsal, lateral. & Volar incision. \\
& The volar compartment is the most frequently involved. & Dorsal incisions. \\
\hline Hand & Ten: & Two longitudinal incisions over 2nd \\
& Hypothenar, & and 4th metacarpals. \\
& Thenar, & Longitudinal incision radial side of \\
& Adductor pollicis, & 1st metacarpal. \\
& N.4 dorsal interosseus, & Longitudinal incision over ulnar side \\
& N.3 palmar interosseus. & of 5th metacarpal. \\
& & Carpal tunnel decompression. \\
\hline Thigh & Two: anterior and posterior & Single lateral incision. \\
\hline Leg & Four: & Two incisions, medial and lateral, of \\
& Anterior, & a minimum of 15 cm. \\
& Lateral, & Some surgeons propose a singular \\
& Posterior (superficial and deep). & lateral approach. \\
\hline Foot & Nine: & Two dorsal incision, dorsomedial \\
& Medial (abductor hallucis and flexor hallucis brevis) & and dorsolateral. \\
& Lateral (abductor digiti minimi and flexor digiti minimi brevis) & A single medial incision is used by \\
& N. 4 interosseus & some authors to release all nine \\
N. 3 central (superficial, central and deep) & compartments. \\
\hline
\end{tabular}

ment and may not be as prone to compartment syndrome as closed fractures. But the small fascial tears that usually result from open fractures do not adequately decompress the compartment.

Soft tissue without fractures and vascular injuries are other important causes of ACS.

Rhabdomyolysis has been reported to be associated with ASC in as much as $23 \%$ of cases in some series $^{3}$. Once tissue necrosis occurs, inflammation and soft tissues welling determine the increase in ICP. Vascular injuries can also cause ACS secondary to compartmental ischemia. Injuries to the popliteal artery have a particularly high incidence of $\mathrm{ACS}^{8}$. Inflammatory response to the initial ischaemic insult can start pressure rises, which can be exacerbated by reperfusion. It is thought that reperfusion starts an inflammatory response against the breakdown products of ischaemic tissue, causing cellular and tissue oedema ${ }^{9}$.

Several theories have been proposed to explain the pathophysiology of ACS.

Circulation of blood from high pressure arteries to low pressure veins is dependent on the pressure differential between these vessels (arteriovenous gradient $-\Delta p$ ).

When $\Delta p$ gradient diminished, the rates of delivery of oxygenated arterial blood and drainage of deoxygenated venous blood decrease. Slow or decreased venous drainage results in the extrusion of fluid into the third compartment, causing tissue oedema, which exacerbates the ICP rise.This establishes avicious cycle, which leads to the collapse of the lymphaticsvesels and eventually of the arterial supply leading to ischaemia and irreversible necrosis. Nerve symptoms such as paraesthesia and tingling begin as early as 30 minutes from the onset of ischemia and irreversible damage may occur as early as 12 hours post-onset ${ }^{10}$.

\section{Diagnosis}

Diagnosing ACS is difficult in clinical practice, and even among expert surgeons there is great variability in the criteria for ACS. A recent study showed that the incidence of fasciotomy varied from 2 to $24 \%$, highlighting the variability of surgical indications and the inconsistency in the clinical diagnosis ${ }^{11}$. Currently, the diagnosis is made on the basis of physical examination and repeated ICP measures, while a method for the accurate and reproducible diagnosis of ACS, especially in the polytraumatized and comatose patients, has yet to be developed ${ }^{12}$.

Usually, 5 "P" are associated with ACS, Pain, Paresthesia, Pallor, Paralysis, and high intra-compartment Pressure. Numbness, tingling and paresthesia are early signs ${ }^{13}$. Pain is severe and disproportionate to the injury or surgery, it is not relieved by painkillers and morphine, and it is worsen by passive stretch of compartment muscles. But in the late stages of ACS pain can be absent. Paresthesia indicates early nerve ischemia, which progresses to anesthesia without intervention. Paresis/paralysis are late features which may indicate both nerve and muscular lesions. Pulselessness is not a diagnostic criteria because peripheral pulses are usually present also when an high compartment pressure is diagnosed. It is important to remind that symptoms should not be considered inisolation but they must be interpreted in light of the patient's personal risk. For example, a 20-year-old man with a tibial fracture complaining only a disproportionate pain should be evaluated with a high index of suspicion, because the likelihood ratio of such a patient developing ACS has been estimated at approximately $25 \%$, assuming a prevalence of $5 \%{ }^{14}$.

Measurement of the ICP is an important tool for diagnosis, and compartment pressures higher than 30 
$\mathrm{mmHg}$ of diastolic blood pressure is significant of compartment syndrome ${ }^{7}$. Mubarak in 1976 showed that high ICP sustained for 6-8 hours results in irreversible soft tissue damage ${ }^{15}$. Many authors currently agree that ICP should be compared with systemic diastolic pressures $(\Delta p)^{16}$. Even if threshold of $\Delta p$ at which surgical intervention is warranted is quoted to be between $30 \mathrm{mmHg}$ and $45 \mathrm{mmHg}$ according different authors, hypotensive patients with ICPs higher than $20 \mathrm{mmHg}$ have an high risk of ACS. Conversely, Park et al. ${ }^{17}$ did not find any statistically significant association between diastolic pressure and ACS.

Non-invasive imaging techniques for determining ICP have been also proposed. These include near-infrared spectroscopy (NIRS) ultrasonic devices and laser Doppler flowmetry ${ }^{12}$. NIRS measures local soft tissue oxygenation approximately 2 to $3 \mathrm{~cm}$ below to the skin, and it could provide continuous monitoring for intracompartmental hypoxia ${ }^{18}$. It could be a sensitive and specific monitor of muscle compartments pressures since tissue oxygenation is inversely correlated with increasing ICP. In an animal study Garr et al. ${ }^{19}$ showed that NIRS was a superior predictor of neuromuscular dysfunction than compartment perfusion pressure.

More recently, it was seen to be effective in differentiated between adequately perfused lateral compartments and poorly perfused deep posterior compartments even in an unresponsive hypotensive patient ${ }^{20}$. Unfortunately this case series involved only 3 patients. These non-invasive techniques may be also particularly useful in paediatric injuries ${ }^{21}$. However, some limitations exist with the use of NIRS, such as effects of skinpigmentation and subcutaneous fat. But Collinge and Kuper ${ }^{22}$ in their prospective study comparing different compartmental measuring devices reported that no single measurement should be used for determination for or against performing fasciotomy, recommending the necessity of clinical correlation.

If regional anesthesia can delay the diagnosis of ACS is still debated ${ }^{23,24}$. Recent researches shows that ischemic pain is largely unaffected by regional anesthesia and that there is no evidence of an association between a peripheral nerve block with a delayed or missed diagnosis of compartment syndrome ${ }^{25}$.

\section{Management of ACS}

Initial management involves removing any casts or dressings overlying the limb. An animal study showed that just cutting the cast reduced ICP by a mean of $65 \%$ with an additional $10-20 \%$ reduction after the padding was cut 26 . However, after removing the cast the patient should be closely examined, and the limb should not be elevated but maintained at heart level to perfuse the compartment ${ }^{10}$. If clinical condition does not improve, fasciotomy is indicated as an emergency procedure to decompress the compartments and prevents irreversible ischemic damage to muscles and peripheral nerves ${ }^{27}$ (Fig. 1). Mubarak and Hargens ${ }^{28}$ suggest that fasciotomy is indicated in normotensive patients with positive clinical findings and with ICP higher than $30 \mathrm{mmHg}$, in uncooperative or unconscious patients with ICPs greater than $30 \mathrm{mmHg}$, and in hypotensive patients with ICPs greater than 20 $\mathrm{mmHg}$. When the fasciotomy is performed, an incision large enough to adequately decompress all the compartments is mandatory (Figs. 2, 3). Prophylactic fasciotomy has been proposed by some authors ${ }^{6}$. But this procedure is not without major complications such as infections and wound closure complications. Furthermore the absence of well conduced randomized control trials made prophylactic fasciotomy a procedure that should be weighed heavily. Surgical decompression is not always indicated if the compartment syndrome has been evident for more than 48 hours and no evidence exists of retained function of the components within the compartment ${ }^{29}$. Fasciotomy is usually performed in the operating room under general or regional anesthesia, but recently bedside fasciotomy under conscious sedation and local anesthesia has also been proposed in selected cases ${ }^{30}$.

The timing of wound closure is still debate in literature. Delaying closure for about seven days allows wound edges approximation at closure. The wound edges need to be frequently irrigated and debrided before final closure, and skin graft may be useful ${ }^{31}$. Dover et al. ${ }^{32}$ reported better results with healing by secondary intention, followed by delayed primary closure and skin grafting, even if the number of patients who heal by secondary intention was smaller than oth-

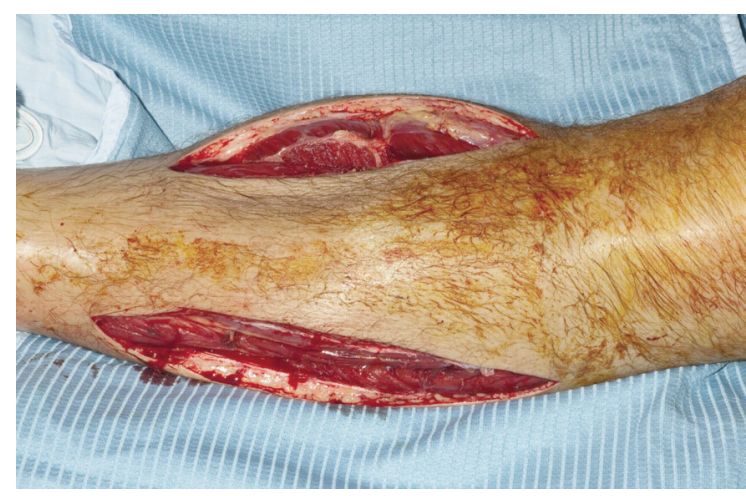

Figure 1. Medial and lateral incisions for leg fasciotomy.

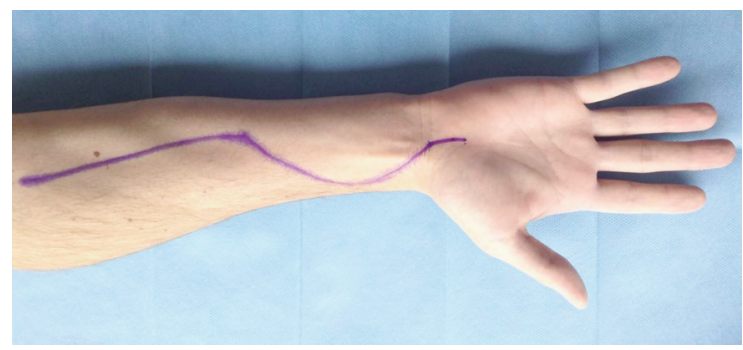

Figure 2. Surgical approach to decompress forearm compartments. The incision should also allow decompression of the carpal tunnel. 


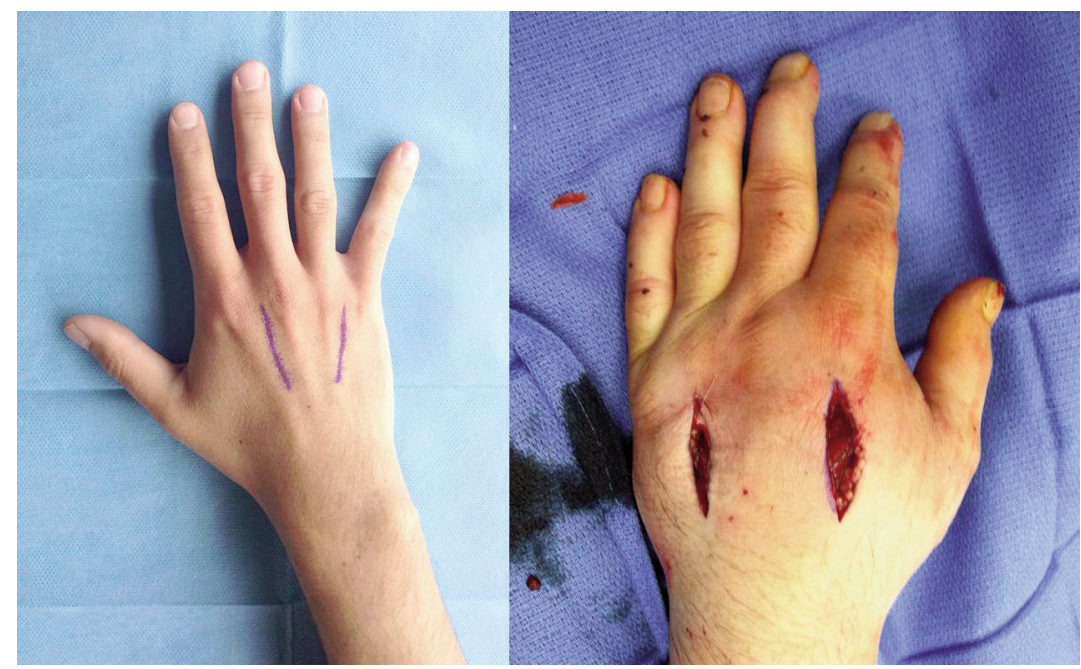

Figure 3. Surgical approach for decompressing interossei compartments and fasciotomy of the hand.

ers groups (6, 39 and 15 patients respectively). Than better results have been reported by patients who received delayed primary closure of the wounds after 8 to 14 days from fasciotomy compared to patients whose wounds were closed after more than 14 days. Primary direct wounds closure is rarely performed and in a systematic review of literature only $15 \%$ received primary closure while most patients (59\%) received delayed primary closure of the fasciotomy incision ${ }^{33}$.

\section{Uncommon causes of ACS}

Uncommon causes of ACS have been described, that highlight the importance of early diagnosis and treatment of these rare conditions.

Isolated vascular injury without fractures is an unusual cause of ACS. Gluteal compartment syndrome resulting from injury to the superior gluteal artery is extremely rare. Only few case reports have been reported after high-energy road traffic accidents, but it may occur also after a relatively minor trauma ${ }^{34}$. Common femoral vessel injury without femoral fracture is another rare cause of ACS of the thigh ${ }^{35}$.

Anticoagulation therapy and all pathologies that impairs blood coagulation and increase the risk of hemorrhage may cause ACS. In fact, it has been reported after lowimpact trauma in patients under anticoagulation therapy $^{36}$ and in patients affected by haemophilia ${ }^{37,38}$. A case of lower limb ACS in a patient under anticoagulation therapy for multiple pulmonary embilism and deep vein thrombosis have also been described ${ }^{39}$.

The aetiology of ACS can also be iatrogenic. Transradial angiography and intervention can result in compartment syndrome if the radial artery perforates and bleeds ${ }^{40}$, but also cases probably secondary to arterial spasm resulted in ischemia of the forearm muscles without artery ruptures was reported ${ }^{41}$.

In extremely rare cases no cause have been found for ACS after extensive medical investigation as in the case of a young 31-year-old lady who developed bilateral compartment syndrome of the forearm ${ }^{42}$.

\section{Conclusion}

Acute compartment syndrome is one of the few true emergencies in orthopedic traumatology, and it is a potentially devastating complication. Necrosis of the soft tissues and peripheral nerves damage may occur if the pressure is not quickly relieved. Despite new research and articles discussing novel diagnostic tools, clinical examination is paramount. The importance of early diagnosis and intervention is emphasized with observations that early fasciotomy is the only effective treatment to prevent permanent disabilities. Rare causes of ACS have been reported in literature, which underline the difficulty in clinical diagnosis and the importance of high clinical suspicion and careful clinical examination. New investigations into reliable methods of diagnosing acute compartment syndrome are needed as well conduced prospective, randomized trials comparing prophylactic and therapeutic fasciotomy.

\section{List of abbreviations}

ICP: intracompartmental pressure ACS: acute compartment syndrome NIRS: near-infrared spectroscopy

\section{Conflict of interest}

We declare none conflict of interest.

The authors declare that this mini-review was conduct according ethically to international standards and as required by the journal as described ${ }^{43}$.

\section{References}

1. Schwartz JT, Brumback RJ, Lakatos R, Poka A, Bathon GH, Burgess AR. Acute compartment syndrome of the thigh-a spectrum of injury. J Bone Joint Surg Am. 1989;71:392-400. 
2. Elsorafy KR, Jm Stone A, Nicol SG. Acute compartment syndrome of the thigh 10 days following an elective primary total hip replacement. Ortop Traumatol Rehabil. 2013;5:269-271.

3. McQueen MM, Gaston P, Court-Brown CM. Acute com $\neg$ partment syndrome. Who is at risk? J Bone Joint Surg Br. 2000; 82:200-203.

4. Taylor RM, Sullivan MP, Mehta S. Acute compartment syndrome: obtaining diagnosis, providing treatment, and minimizing medicolegal risk. Curr Rev Musculoskelet Med. 2012; 5:206-213.

5. Erdos J, Dlaska C, Szatmary P, Humenberger M, Vecsei V, Hajdu S. Acute compartment syndrome in children: a case series in 24 patients and review of the literature. Int Orthop. 2011;35:569-575.

6. Mauser N, Gissel H, Henderson C, Hao J, Hak D, Mauffrey C. Acute Lower-leg Compartment Syndrome. Orthopedics. 2013;36:619-624.

7. McQueen MM, Court-Brown CM. Compartment monitoring in tibial fractures. The pressure threshold for decompression. J Bone Joint Surg Br. 1996;78:99-104.

8. Abouezzi Z, Nassoura Z, Ivatury RR, Porter JM, Stahl WM. A critical reappraisal of indications for fasciotomy after extremity vascular trauma. Arch Surg. 1998;133:547-551.

9. Percival TJ, White JM, Ricci MA. Compartment syndrome in the setting of vascular injury. Perspect Vasc Surg EndovascTher. 2011;23:119-124.

10. Mabvuure NT, Malahias M, Hindocha S, Khan W, Juma A. Acute Compartment Syndrome of the Limbs: Current Concepts and Management. Open Orthop J. 2012;6:535-543.

11. O'Toole RV, Whitney A, Merchant N, et al. Variation in diagnosis of compartment syndrome by surgeons treating tibial shaft fractures.J Trauma. 2009;67:735-741.

12. Harvey EJ, Sanders DW, Shuler MS, et al. What's new in acute compartment syndrome? J Orthop Trauma. 2012;26: 699-702.

13. Konstantakos EK, Dalstrom DJ, Nelles ME, Laughlin RT, Prayson MJ. Diagnosis and management of extremity compartment syndromes: an orthopaedic perspective. Am Surg. 2007;73:1199-1209.

14. Ulmer $\mathrm{T}$. The clinical diagnosis of compartment syndrome of the lower leg: are clinical findings predictive of the disorder? J Orthop Trauma. 2002;16: 572-577.

15. Mubarak SJ, Hargens AR, Owen CA, Garetto LP, Akeson WH. The wick catheter technique for measurement of intramuscular pressure. A new research and clinical tool. J Bone Joint Surg Am. 1976;58:1016-20.

16. Whitesides TE, Haney TC, Morimoto K, Harada H. Tissue pressure measurements as a determinant for the need of fasciotomy. Clin Orthop Relat Res. 1975;113:43-51.

17. Park S, Ahn J, Gee AO, Kuntz AF, Esterhai JL. Compartment syndrome in tibial fractures. J Orthop Trauma. 2009;23:514518.

18. Cole AL, Herman RA, Heimlich JB, Ahsan S, Freedman BA, Shuler MS. Ability of near infrared spectroscopy to measure oxygenation in isolated upper extremity muscle compartments. J Hand Surg Am. 2012;37:297-302.

19. Garr JL, Gentilello LM, Cole PA, et al. Monitoring for compartmental syndrome using near-infrared spectroscopy: a noninvasive, continuous, transcutaneous monitoring technique. J Trauma. 1999;46:613-616.

20. Shuler MS, Reisman WM, Kinsey TL, et al. Correlation between muscle oxygenation and compartment pressures in acute compartment syndrome of the leg. J Bone Joint Surg Am. 2010;92:863-870.

21. Tobias JD, Hoernschemeyer DG. Near-infrared spectroscopy identifies compartment syndrome in an infant. J Pediatr Orthop. 2007;27:311-313.

22. Collinge $\mathrm{C}$, Kuper M. Comparison of three methods for mea- suring intracompart?mental pressure in injured limbs of trauma patients. J Orthop Trauma. 2010;24:364- 368.

23. Walker BJ, Noonan KJ, Bosenberg AT. Evolving compartment syndrome not masked by a continuous peripheral nerve block: evidence-based case management. Reg Anesth Pain Med. 2012;37:393-397.

24. Kucera TJ, Boezaart AP. Regional Anesthesia Does Not Consistently Block Ischemic Pain: Two Further Cases and a Review of the Literature. Pain Med. 2014;15:316-319.

25. Karagiannis G, Hardern R. Best evidence topic report. No evidence found that a femoral nerve block in cases of femoral shaft fractures can delay the diagnosis of compartment syndrome of the thigh. Emerg Med J. 2005;22:814.

26. Garfin SR, Mubarak SJ, Evans KL, Hargens AR, Akeson WH. Quantification of intracompartmental pressure and volume under plaster casts. J Bone Joint Surg Am. 1981;63:449-453.

27. Ritenour AE, Dorlac WC, Fang R, et al. Complications after fasciotomy revision and delayed compartment release in combat patients. J Trauma. 2008;64:153-161.

28. Mubarak SJ, Hargens AR. Acute compartment syndromes. Surg Clin North Am. 1983;63:539-565.

29. Konstantakos EK, Dalstrom DJ, Nelles ME, Laughlin RT, Prayson MJ. Diagnosis and management of extremity compartment syndromes: an orthopaedic perspective. Am Surg. 2007;73:1199-1209.

30. Ebraheim NA, Abdelgawad AA, Ebraheim MA, Alla SR. Bedside fasciotomy under local anesthesia for acute compartment syndrome: a feasible and reliable procedure in selected cases. J OrthopTraumatol. 2012;13:153-157.

31. Gourgiotis S, Villias C, Germanos S, Foukas A, Ridolfini MP. Acute limb compartment syndrome: a review. J Surg Educ. 2007;64:178-186.

32. Dover M, Memon AR, Marafi H, Kelly G, Quinlan JF. Factors associated with persistent sequelae after fasciotomy for acute compartment syndrome. J Orthop Surg. 2012;20:312-325.

33. Ojike NI, Roberts CS, Giannoudis PV. Compartment syndrome of the thigh: a systematic review. Injury. 2010;41(2): 133-136.

34. Smith A, Chitre V, Deo H. Acute gluteal compartment syndrome: superior gluteal artery rupture following a low energy injury. BMJ Case Rep. 2012;17.

35. Davaine JM, Lintz F, Cappelli M, et al. Acute compartment syndrome of the thigh secondary to isolated common femoral vessel injury: an unusual etiology. Ann Vasc Surg. 2013;27:802.

36. Aliano K, Gulati S, Stavrides S, Davenport T, Hines G. Low-impact trauma causing acute compartment syndrome of the lower extremities. Am J Emerg Med. 2013;31:890.

37. Jones G, Thompson K, Johnson M. Acute compartment syndrome after minor trauma in a patient with undiagnosed mild haemophilia B. Lancet. 2013;16;382(9905):1678.

38. Rodriguez-Merchan EC. Acute compartment syndrome in haemophilia. Blood Coagul Fibrinolysis. 2013;24:677-682.

39. Newman PA, Deo S. Non-traumatic compartment syndrome secondary to deep vein thrombosis and anticoagulation. BMJ Case Rep. 2014;17.

40. Kanei Y, Kwan T, Nakra NC, et al. Transradial cardiac catheterization: a review of access site complications. Catheter Cardiovasc Interv. 2011;78: 840-846.

41. Araki $\mathrm{T}$, Itaya $\mathrm{H}$, Yamamoto $\mathrm{M}$. Acute compartment syndrome of the forearm that occurred after transradial intervention and was not caused by bleeding or hematoma formation. Catheter Cardiovasc Interv. 2010;75:362-365.

42. Dalton DM, Munigangaiah S, Subramaniam T, McCabe JP. Acute bilateral spontaneous forearm compartment syndrome. Hand Surg. 2014;19:99-102.

43. Padulo J, Oliva F, Frizziero A, Maffulli N. Muscles, Ligaments and Tendons Journal. Basic principles and recommendations in clinical and field science. MLTJ. 2013;4:250-252. 